COPD guidelines

\section{NICE guidance for COPD}

\section{Halpin}

\section{A further step in the process of developing better service and standards of care for patients with COPD}

$\checkmark$ g he full version of the new NICE guidelines on the management of chronic obstructive pulmonary disease (COPD) is published as a supplement to this issue of Thorax. ${ }^{1}$ These guidelines have been developed for the National Institute for Clinical Excellence (NICE) by the National Collaborating Centre for Chronic Conditions (NCC-CC) based at the Royal College of Physicians, London with the involvement of many members of the British Thoracic Society (BTS). The Guideline Development Group and Consensus Reference Group involved in the production of the guidelines included members with diverse professional backgrounds and, crucially, also included patient representatives. The scope of the guidelines is wide. They address the diagnosis and assessment of people with COPD as well as the pharmacological and non-pharmacological management of stable disease and exacerbations.

With the recent update to the GOLD guidelines ${ }^{2}$ and the forthcoming publication of joint guidelines by the American Thoracic Society (ATS) and the European Respiratory Society (ERS), the need for new British guidelines could be questioned. I have no doubt that there is a role for these guidelines as they address issues such as pulmonary rehabilitation from a British perspective and, most importantly, are truly evidence-based. Moreover, in the absence of a National Service Framework for respiratory medicine, and the reality that such a framework is unlikely to be introduced in the near future, these NICE guidelines offer the best hope of raising the standards of care of this common disabling chronic disease.

The key issues for practising clinicians are:

- What is new in these guidelines?

- How do they relate to other international guidelines?

Significant changes in practice have evolved since the BTS guidelines on the management of COPD were published in $1997,{ }^{3}$ and more evidence is available about the effects of treatments such as inhaled steroids and long acting bronchodilators. The guidelines also make updated recommendations on the diagnosis and assessment of COPD. This was one of the areas that received most comments during the two stage consultation process during guideline development.

\section{DIAGNOSIS AND ASSESSMENT OF COPD}

The guidelines make the bold statement that, in most cases, the diagnosis of COPD can be made on the basis of a good history with confirmation of the presence of airflow limitation using spirometry. They do not recommend assessment of the change in forced expiratory volume in 1 second $\left(\mathrm{FEV}_{\mathrm{l}}\right)$ in response to a single dose of an inhaled bronchodilator or a short course of oral or inhaled corticosteroids. A belief has emerged that the results of such an assessment made on a single occasion can categorically distinguish COPD from asthma. Moreover, it is believed that by making this measurement it is possible to identify a significant number of patients who have asthma, but who would otherwise be condemned to the diagnostic and therapeutic ignominy of being misdiagnosed as having COPD. It has also been thought that the results of such a measurement can be used to predict the long term response to treatment. There are undoubtedly a few patients in whom the history will not be clear cut and in whom a large change in $\mathrm{FEV}_{1}$ may help to identify a reversible component (an absolute change in $\mathrm{FEV}_{1}$ of $400 \mathrm{ml}$ is suggested as the discriminator). The principal objection to our recommendation is that, unless the test is done in everyone, patients showing such a response will still be missed. There are a number of problems with such an approach. The distribution of changes in $\mathrm{FEV}_{1}$ following a single dose of a bronchodilator is normally distributed. ${ }^{4}$ It is not bimodal and any cut off used to distinguish two subgroups is therefore entirely arbitrary. Furthermore, we know that, if the measurement is repeated on different occasions, different results may be obtained. ${ }^{5}$ Finally, depending on the agent used to produce the change in $\mathrm{FEV}_{1}$-for example, salbutamol from a metered dose inhaler, nebulised salbutamol, or oral corticosteroids-different responses may be produced. ${ }^{6}$ The new ATS/ERS guidelines also recognise these limitations and do not advocate assessing the response to a single dose of a bronchodilator or a short course of corticosteroids as part of the diagnostic process, and the next revision of the GOLD guidelines will also dispense with this approach (personal communication, $\mathrm{P}$ M A Calverley). There is good evidence that the response to a single dose of a bronchodilator or short courses of corticosteroids has no bearing on the long term response to treatment.

The guidelines do recognise that there may be a very few patients who appear to have COPD on the basis of the history but who show significant clinical responses to inhaled therapy. In these patients it is important to review the diagnosis and this we believe constitutes a much more meaningful "reversibility test". The results of this review of response to treatment forms part of the diagnostic process and we believe fulfils the quality marker in the new general practice contract in the UK.

\section{MANAGEMENT OF COPD}

The guidelines have moved away from the linear approach to COPD management embodied in the "escalator" presented in the 1997 BTS guidelines. We recognise that COPD is a heterogeneous condition that affects patients in different ways, and that a patient centred approach to their management is required rather than a unidirectional stepwise approach. This may appear more complicated on paper but is simple to apply in practice and is necessary to achieve optimal control of symptoms. There are still no validated severity assessment tools that encompass the multidimensional nature of the disease, and we therefore continue to recommend using $\mathrm{FEV}_{1}$ as a percentage of the predicted as a marker of the severity of airflow obstruction, but acknowledge that this may not reflect the impact of the disease in that individual. We have changed the $\mathrm{FEV}_{1}$ cut off points and these now match those in the updated GOLD and new ATS/ERS guidelines, although the terminology is slightly different: an $\mathrm{FEV}_{1}$ of $50-80 \%$ predicted constitutes mild airflow obstruction, 30$49 \%$ moderate airflow obstruction, and $<30 \%$ severe airflow obstruction.

Extensive literature searching and professional systematic reviewing was used to assess the evidence base for treatment. The biggest areas of change 
from the previous BTS guidelines concern the use of long acting bronchodilators, inhaled corticosteroids, and mucolytic therapy. There is now persuasive evidence of benefit from the use of long acting bronchodilators, both $\beta_{2}$ agonists and anticholinergic agents, and their use is recommended in patients who remain symptomatic despite the use of short acting bronchodilators. We recommend that the criteria for their use and the assessment of their benefits should not depend solely on lung function changes but should include simple questions about changes in symptoms, exercise tolerance, and quality of life.

We believe that the role of inhaled corticosteroids has also become clearer and recommend that they should be used in patients with an $\mathrm{FEV}_{1}<50 \%$ predicted and a history of two or more exacerbations in the previous year in an attempt to reduce the future exacerbation rate. In these circumstances they will generally be used in combination with a long acting bronchodilator. This remains a highly complex and somewhat controversial area where approaches to data analysis are still evolving. Hopefully, by the time of the next guideline revision, these issues will have been resolved. Mortality data from prospective randomised trials of these treatments that are currently in progress should help us to interpret these findings clinically and, if necessary, to revise our recommendations.

Despite widespread use in Europe, mucolytic therapy has not been used in the UK and, until early last year, mucolytic drugs were "black listed" in the NHS. There is good evidence for their efficacy in reducing exacerbations and improving symptoms in patients with chronic bronchitis and some direct evidence of benefit in patients with COPD. We believe that they should be tried in patients with a chronic cough productive of sputum and, if clinical benefit is observed, they should be continued.

The guidelines recognise the importance of multidisciplinary approaches to the management of COPD. Pulmonary rehabilitation is rightly recommended for all patients who are disabled by COPD, and we hope that this may facilitate the universal provision of pulmonary rehabilitation programmes. Hospital at home and assisted discharge schemes are also new approaches to the management of exacerbations of COPD. These schemes appear to work and relieve pressure on hospital beds, and are recommended where local circumstances require. NICE guidelines do not make recommendations about how services should be provided and organised: these are matters for local clinicians and commissioners, but the needs for the services are clearly delineated.

The recommendations on oxygen therapy in COPD are largely in line with those contained in the Royal College of Physicians report commissioned by the Department of Health. ${ }^{7}$ The Department has recently signalled its intention to review the provision of oxygen services. The final conclusions of this review were not known at the time that the recommendations were finalised, but we have no reason to believe that the conclusions will conflict with the recommendations contained in these guidelines. We understand that they are likely to focus on the process of assessing and prescribing oxygen rather than the criteria for deciding who needs oxygen therapy.

Exacerbations are now recognised as key events in the natural history of COPD and appropriate emphasis is given to their prevention and management. Non-invasive ventilation has been shown to be the treatment of choice for episodes of respiratory failure associated with exacerbations and its use is recommended. Again, it is hoped that this will facilitate the universal provision of such services.

\section{CONCLUSION}

We hope that these guidelines will help encourage clinicians to manage COPD better. Unlike the recent BTS/SIGN asthma guidelines ${ }^{8}$ which provide evidence to support management strategies already in widespread use, there is a lot that is new in these COPD guidelines that is not happening in practice at present but which will hopefully become universal over the next few years. The Guideline Development Group has identified seven key priorities for implementation-areas where it was felt that recommendations were likely to have the biggest impact on the management of COPD. These key priorities cover:

- diagnosis of COPD;

- smoking cessation;

- effective inhaled treatment;

- pulmonary rehabilitation;
- use of non-invasive ventilation for exacerbations;

- effective prevention and management of exacerbations; and

- importance of multidisciplinary working.

The BTS COPD Consortium will be working to ensure that the key messages contained in the guideline reach all relevant health professionals. As NICE guidelines, the recommendations also reach health commissioners who will be expected to respond and implement the guidance. Let us hope that this is a further significant step in the process of developing better service and standards of care for patients with respiratory diseases.

Thorax 2004:59:181-182.

doi: $10.1136 /$ thx.2004.021113

Correspondence to: D Halpin, Consultant Physician \& Senior Lecturer in Respiratory Medicine, Chair, Guideline Development Group, Royal Devon \& Exeter Hospital, Exeter, UK; d.m.g.halpin@ex.ac.uk

Declarations of interest for members of the Guideline Development Group are available from the NCC-CC.

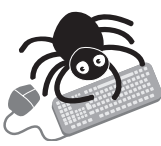

The COPD guidelines are available online at the Thorax website (http:// thorax.bmijournals.com/ content/vol59/suppl_1)

\section{REFERENCES}

1 National Institute for Clinical Excellence (NICE) Chronic obstractive pulmonary disease: national clinical guideline for management of chronic obstructive pulmonary disease in adults in primary and secondary care. Thorax 2004:59(Suppl I).

2 Fabbri LM, Hurd SS. Global strategy for the diagnosis, management and prevention of COPD: 2003 update. Eur Respir J 2003;22:1-2.

3 COPD Guidelines Group of the Standards of Care Committee of the BTS. BTS guidelines for the management of chronic obstructive pulmonary disease. Thorax 1997;52(Suppl 5):S1-28.

4 Anthonisen NR, Wright EC. Bronchodilator response in chronic obstructive pulmonary disease. Am Rev Respir Dis 1986;133:814-9.

5 Calverley PM, Burge PS, Spencer S, et al. Bronchodilator reversibility testing in chronic obstructive pulmonary disease. Thorax 2003;58:659-64.

6 Nisar M, Walshaw M, Earis JE, et al. Assessment of reversibility of airway obstruction in patients with chronic obstructive airways disease. Thorax 1990;45:190-4.

7 Royal College of Physicians. Domiciliary oxygen therapy services. Clinical guidelines and advice for prescribers. London: Royal College of Physicians, 1999.

8 British Thoracic Society/Scottish Intercollegiate Guideline Network. British guideline on the management of asthma. Thorax 2003;58(Suppl I):i1-94. 


\section{Peer review and NICE COPD guidelines}

\section{J A Wedzicha}

\section{New COPD guidelines from NICE}

O ver the years Thorax has published a number of valuable clinical guidelines, and these have been subject to formal peer review as for any original paper. ${ }^{1-13}$ With this issue of Thorax we publish as a supplement the full version of the clinical guidelines for the management of chronic obstructive pulmonary disease (COPD). ${ }^{14}$ Unlike the previous guidelines mainly produced through the Standards of Care Committee of the British Thoracic Society (BTS), these COPD guidelines have been developed by the NICE (National Institute for Clinical Excellence) Collaborating Centre for Chronic Conditions.

These COPD guidelines were not sent out for further review once received by Thorax as the review process within the guideline development programme has been formal and carried out according to the regulations for guideline development established by NICE. The guideline was developed and produced by the Guideline Development Group (GDG) which met regularly over an 18 month period and consisted of representatives of the BTS, nurses, physiotherapists, and patients. All the recommendations were then voted on by a larger multiprofessional group called the Consensus Reference Group (CRG).

Once all the recommendations were agreed upon by the GDG and CRG, the final draft was sent to stakeholders for comment and also placed on the NICE website. The various stakeholders included the Standards of Care Committee of the BTS who discussed the guidelines at one of their meetings. All the comments from the various stakeholders were then collated and responses were prepared. Any issues that arose from this round of consultation were discussed at a further meeting of the GDG and revisions to the guidelines were agreed. The next draft of the guideline was again placed on the NICE website for a second round of consultation. Any comments that were sent in about the guidelines were again considered, responded to, and the guideline revised. NICE has its own Guideline Review Panel which deals with both the content of the guideline and the methodology, and this panel also reviewed the second round version and raised a number of issues.

The process of guideline development through NICE does not allow for peer review at the time of submission to the journal. However, in view of the detailed process that had been followed in the guideline development, the Editors of Thorax were satisfied that the review process was fair and rigorous and that further peer review was not required before publication.

In addition, I have been a member of both the GDG and the CRG for these guidelines and have thus contributed directly to them. Membership of these guideline groups has allowed me to observe directly the review process during the guideline development programme. My research group has a major interest in exacerbations of COPD, and I have received grant funding for studies of COPD exacerbations together with honoraria for lectures and attendance at advisory boards from a number of pharmaceutical companies. Full details of my competing interests are located on the Thorax journal website at www.thoraxjnl.com.

Thorax 2004;59:183.

doi: $10.1136 /$ thx.2004.021543

Correspondence to: Professor J A Wedzicha, Editor in Chief, Thorax Editorial Office, 17 Doughty Street, London WCIN 2PL, UK; J.A.Wedzicha@qmul.ac.uk

\section{REFERENCES}

1 Joint Tuberculosis Committee of the British Thoracic Society. Control and prevention of tuberculosis in the United Kingdom: code of practice 2000. Thorax 2000;55:887-901.

2 British Thoracic Society. British Thoracic Society guidelines on diagnostic flexible bronchoscopy. Thorax 2001;56(Suppl I):i1-21.

3 British Thoracic Society, Society of Cardiothoracic Surgeons of Great Britain, and Ireland Working Party. Guidelines on the selection of patients with lung cancer for surgery. Thorax 2001;56:89-108.

4 British Thoracic Society Standards of Care Subcommittee on Pulmonary Rehabilitation. Pulmonary rehabilitation. Thorax 2001;56:827-834.

5 British Thoracic Society. BTS guidelines for the management of community acquired pneumonia in adults. Thorax 2001;56(Suppl IV):iv1-64.

6 British Thoracic Society. BTS guidelines for the management of community acquired pneumonia in childhood. Thorax 2002;57(Suppl I):i1-24.

7 British Thoracic Society. Non-invasive ventilation in acute respiratory failure. Thorax 2002;57:192-211.

8 British Thoracic Society. Managing passengers with respiratory disease planning air travel: British Thoracic Society recommendations. Thorax 2002;57:289-304

9 British Thoracic Society/Scottish Intercollegiate Guidelines Network. British guideline on the management of asthma. Thorax 2003;58(Suppl I):i1-94.

10 British Thoracic Society. British Thoracic Society guidelines for the management of suspected acute pulmonary embolism. Thorax 2003;58:470-83.

11 British Thoracic Society. BTS guidelines for the management of pleural disease. Thorax 2003;58(Suppl II):ii1-59.

12 British Thoracic Society. BTS guidelines on respiratory aspects of fitness for diving. Thorax 2003;58:3-13.

13 Manhire A, Charig M, Clelland C, et al. Guidelines for radiologically guided lung biopsy. Thorax 2003;58:920-36.

14 National Institute for Clinical Excellence (NICE). Chronic obstructive pulmonary disease: national clinical guideline for management of chronic obstructive pulmonary disease in adults in primary and secondary care. Thorax 2004;59(Suppl I). 


\section{Smoking, cadmium, and emphysema}

\section{J Hendrick}

\section{Does cadmium contribute to the development of smoking induced emphysema?}

$M$ ost respiratory physicians recognise that chronic exposure to respirable cadmium in the workplace may lead to emphysema. What may come as a surprise is that cadmium is a constituent of tobacco and hence cigarette smoke, and so is inhaled outside the workplace by all smokers. The question arises whether inhaled cadmium may contribute to, or even be the principal cause of, smoking induced emphysema.

Mannino and colleagues have taken advantage of the Third US National Health and Nutritional Examination Survey (NHANES III) to investigate the matter, since it allowed them to compare creatinine adjusted urinary cadmium levels with spirometric measurements in as many as 16024 subjects, representative of the adult US population. Their findings are presented in this issue of Thorax. ${ }^{1}$ Not only was there an increasing trend in urinary cadmium levels from never, through former, to current smokers, but among the current and former smokers (though not the never smokers) urinary cadmium was correlated negatively with forced expiratory volume in 1 second $\left(\mathrm{FEV}_{1}\right)$ and the ratio of $\mathrm{FEV}_{1}$ to forced vital capacity (FVC) after adjustments for potential confounders. They concluded that cadmium might indeed contribute importantly to tobacco related lung disease.

Is this plausible? If so, is it likely? Neither question can be answered easily, and there is a possible alternative explanation for the observed association. Urinary cadmium may simply be a marker of cumulative exposure to tobacco smoke.

\section{CADMIUM SOURCES, UPTAKE, AND METABOLISM}

Cadmium occurs within zinc, copper, and lead ores and its concentration in soil varies widely (typically 0.01$7.0 \mathrm{ppm})$. This influences the amount in local drinking water and the amount delivered into tobacco leaves and other plants. In the absence of occupational exposure, cadmium enters the body in trace amounts within drinking water and foodstuffs, and within tobacco smoke. Food intake of cadmium averages 10-25 $\mu \mathrm{g} / \mathrm{day}$, but may exceed this considerably if shellfish is prominent in the diet. Up to $30 \mu \mathrm{g}$ of cadmium contaminates a pack of cigarettes. However, only a small proportion of this (median $2.74 \mu \mathrm{g}$ per pack in one study, as Mannino and colleagues point out) is transferred to mainstream smoke, and only $20-50 \%$ of the amount inhaled is absorbed. An even smaller proportion $(2-6 \%)$ of ingested cadmium is absorbed. The net outcome is that body burden of never smokers.

Cadmium entering the blood is retained chiefly within the liver and kidneys, where most becomes complexed with metallothionein. This makes it relatively innocuous, but that which is not complexed is potentially toxic-especially to the kidneys, but also to the lungs and other organs. The (many years) and the body's store generally increases until late middle age to a normal total of $10-30 \mathrm{mg}$. The little that is re-released into the blood may become re-absorbed temporarily within tubular cells of the kidney and then dissociated, allowing the potential for delayed and ongoing toxicity. It is unclear whether a similar mechanism operates in the lungs. The daily excretion of cadmium in urine is a useful, if crude, marker of the total body burden. Normal excretion averages $1-2 \mu \mathrm{g} /$ day at most, but the range can be wide. By contrast, the blood cadmium level is a poor reflection of the total burden and relates more closely to recent exposure.

\section{CADMIUM MEASUREMENTS AND THE EFFECTS OF CHRONIC LOW LEVEL EXPOSURE}

Proteinuria is usually considered the earliest sign of toxicity from chronic low level exposure to cadmium, whether by ingestion or inhalation, following which cadmium is less readily retained by the kidney. Urinary excretion is then a less reliable measure of the body burden. In a population with environmental (but not occupational) exposure zinc smelters, a small risk of perturbed current smokers have roughly twice the complexed cadmium has a long half life living at various distances from regional renal function was noted from an initial study only when urinary cadmium levels exceeded 2-4 $\mu \mathrm{g} /$ day. When a nested cohort of 593 men and women selected to have higher than average exposures was followed for 5 years there was no indication of progressive renal damage. The mean urinary cadmium level was almost exactly $1 \mu \mathrm{g} /$ day initially and diminished by about $15 \%$ over the 5 years. ${ }^{2}$

In studies of populations with respirable as well as gastrointestinal exposure, the presumed risk of proteinuria has not been increased unless urinary excretion reached $10 \mu \mathrm{g} / \mathrm{g}$ creatinine (men usually excrete 1-2 g creatinine daily, women a little less) or airborne levels exceeded $20-50 \mu \mathrm{g} / \mathrm{m}^{3}$. Such threshold estimates may be conservative, and in a study of 90 workers exposed to cadmium dusts for up to 20 years (average 7.5 years) of whom 75 were smokers, a mean urinary excretion of cadmium of $23 \mu \mathrm{g} / \mathrm{g}$ creatinine (50 times that of the NHANES III smokers) was not associated with any excess proteinuria compared with unexposed controls. ${ }^{3}$ Up to 1996 the lowest mean airborne levels reported to cause toxicity in individuals were $88 \mu \mathrm{g} / \mathrm{m}^{3}$ over 8.6 years in a man and $129 \mu \mathrm{g} / \mathrm{m}^{3}$ over 20 years in a woman. ${ }^{4}$

Emphysema was the primary end point in a study of 99 men, mostly retired, who had worked for at least 1 year in a copper-cadmium alloy factory. ${ }^{5}$ Lung function evidence of excess emphysema was associated with liver cadmium levels as measured by neutron activation analysis. Airborne levels of exposure measured with static and personal samplers during the relevant periods of employment (1926-83) had ranged between 600 and $34 \mu \mathrm{g} / \mathrm{m}^{3}$. The mean liver cadmium level was calculated at $26.1 \mathrm{ppm}$, more than 40 times that of "unexposed" controls with similar smoking habits (0.6 ppm).

\section{NO-CADMIUM IN TOBACCO SMOKE IS NOT A LIKELY CAUSE OF EMPHYSEMA}

If cadmium is a constituent of tobacco smoke, it is to be expected that urinary cadmium levels will increase as pack years accumulate. It may simply be an innocent marker of cumulative exposure to tobacco smoke, much as expired carbon monoxide, blood carboxyhaemoglobin, serum thiocyanate, or serum/ urinary/salivary cotinine are innocent markers of acute exposure.

In the NHANES III population the mean creatinine adjusted urinary cadmium levels of current and former smokers $(0.46$ and $0.32 \mu \mathrm{g} / \mathrm{g}$ creatinine, respectively) were no more than 2.0 and 1.4-fold that of the never smokers $(0.23 \mu \mathrm{g} / \mathrm{g}$ creatinine). The level among 
the smokers was thus twice that of the never smokers-and so consistent with general experience-but it was very low indeed compared with working populations exposed to cadmium, even populations without any apparent adverse effect on kidneys or lungs. If urinary cadmium provides a reliable measure of the cumulative dose of cadmium absorbed by the lungs and gut, and if cadmium delivered to the lungs through the circulation is as hazardous as cadmium delivered in inspired air, these observations imply a "dose" threshold for inducing emphysema that is similar to, or only marginally above, the average dose retained without apparent ill effect in the population at large from food and water. This is just plausible, but it is not likely.

An obstructive impairment of ventilatory function in the NHANES III population was correlated with urinary cadmium levels even after adjustment for pack years and cotinine level-a point in favour of cadmium being relevant independently. Although variability in puff frequency and depth of inhalation may play a role in the implicit discordance between reported pack years and urinary cadmium, the major factor could be the notorious inaccuracy with which smokers estimate their levels of consumption. If all underestimate by similar degrees, the effect on epidemiological investigation would be minor, but the likelihood is that a minority provide accurate estimates while the majority provide estimates with variable degrees of inaccuracy. In such circumstances, urinary cadmium may simply provide a more accurate reflection of cumulative tobacco consumption.

\section{YES-CADMIUM IN TOBACCO SMOKE IS A PLAUSIBLE CAUSE OF EMPHYSEMA}

Mannino and colleagues offer a different explanation for any discordance between smoking histories and urinary cadmium levels. They suggest, reasonably, that there may be important differences in the handling and metabolism of cadmium. Biological variability in absorbing and metabolising the same inhaled dose of an emphysema inducing component of tobacco smoke could well help to explain the striking variability in susceptibility that is characteristic of smoking related diseases.

There is a clear example of genetic susceptibility to emphysema. Subjects with $\alpha_{1}$-antitrypsin deficiency are less able to protect themselves from injury from proteases generated from inflammatory insults to the lung. Curiously, of a number of trace metals investigated, cadmium appears to be the only one to reduce the serum concentration of $\alpha_{1}$ antitrypsin and so depress trypsin inhibition. ${ }^{6}$ In addition, it adversely affects fibroblast production of procollagen and interferes with the synthesis of proteoglycans. ${ }^{7}$ Cadmium thus diminishes the lung's capacity to produce connective tissue proteins and so prevent the disruption characteristic of emphysema. Genetic variability in these biological functions would weaken any relation between "dose" and response, and an inability to allow for different degrees of susceptibility between individuals in populations exposed to hazardous agents poses a major problem in epidemiological research.

Mannino and colleagues did, of course, study a sample of a normal population, not subjects selected because they had worked with cadmium or had known COPD. The dose-response relation between cadmium and ventilatory function was necessarily focused at low dose levels, and their ability to demonstrate it undoubtedly owed much to the great power generated by so many participants. The relation could still be causal even if the actual effect at such low levels of exposure is minor and not detectable by studies of smaller populations with higher levels of exposure.

This assumes that the accumulated body burden of cadmium (and the more readily measured urinary excretion of cadmium) does reasonably reflect the risk of toxicity from inhaled and ingested sources alike. This may not be so. It is interesting that "doses" of zinc oxide that cause metal fume fever when inhaled have no comparable effect when administered by ingestion or intravenous injection. ${ }^{8}$ Thus, zinc has to be inhaled to produce this particular type of toxic reaction. This might explain why Mannino and colleagues found no relation between urinary cadmium and ventilatory function in the never smokers. The small difference in urinary excretion levels between the smokers and never smokers in their study may consequently be of limited significance.

If there is considerable variability in metabolic pathways relevant to absorption, storage, injury, and repair so that some individuals are particularly susceptible even at low levels of relevant exposure, then it is plausible that cadmium plays at least a contributory role in the development of smoking induced emphysema.

Incidentally, cadmium is also recognised to cause lung cancer ...

\section{ACKNOWLEDGEMENT}

I am grateful to Professor P G Blain for advice and guidance.

Thorax 2004;59: 184-185.

doi: $10.1136 /$ thx.2003.018432

Correspondence to: D J Hendrick, Department of Respiratory Medicine, Royal Victoria Infirmary, University of Newcastle upon Tyne, Newcastle upon Tyne NE1 4LP, UK; d.j.hendrick@ncl.ac.uk

\section{REFERENCES}

1 Mannino DM, Holguin F, Greves HM, et al. Urinary cadmium levels predict lower lung function in current and former smokers: data from the Third National Health and Nutrition Examination Survey. Thorax 2004;59:194-8.

2 Hotz P, Buchet JP, Bernard A, et al. Renal effects of low-level environmental cadmium exposure: 5 -year follow-up of a subcohort from the Cadmibel study. Lancet 1999;354:1508-13.

3 Stokinger HE. The metals. In: Clayton DD, Clayton JE, eds. Patty's industrial hygiene and toxicology, 3rd ed. New York: Wiley \& Sons, 1981:1576.

4 Lewis RJ. Sax's dangerous properties of industrial materials, 9th ed. New York: Van Nostrand Reinhold, 1996.

5 Davison AG, Fayers PM, Taylor AJ, et al. Cadmium fume inhalation and emphysema. Lancet 1988; 1:663-7.

6 Chowdhury P, Louria DB. Influence of cadmium and other trace metals on human alphalantitrypsin: an in vitro study. Science 1976;191:480-1.

7 Chambers RC, Laurent GJ, WestergrenThorsson G. Cadmium inhibits proteoglycan and procollagen production by cultured human lung fibroblasts. Am J Respir Cell Mol Biol 1998; 19:498-506.

8 McMillan G. Welding. In: Hendrick DJ, Burge PS, Beckett WS, Churg A, eds. Occupational disorders of the lung: recognition, management, and prevention. London: WB Saunders, 2002:467-79. 


\title{
Examining the influence of early life socioeconomic position on pulmonary function across the life span: where do we go from here?
}

\author{
B Jackson, R J Wright, L D Kubzansky, S T Weiss
}

Factors to consider in future research on the relationship between early life socioeconomic position and adult lung function

C nsistent with the Barker hypothesis of the early life origins of body of research suggests a relationship between social disadvantage in early life and adverse health outcomes. ${ }^{2}$ In this issue of Thorax a paper by Lawlor et $a l^{3}$ presents evidence for inverse associations between markers of childhood socioeconomic position (SEP) and later life pulmonary function. The authors found that, as the number of indicators of childhood poverty increased, the levels of forced expiratory volume in l second $\left(\mathrm{FEV}_{1}\right)$, forced vital capacity (FVC), and forced mid expiratory flow rate $\left(\mathrm{FEF}_{25-75}\right)$ decreased. Limitations of the study included a moderate response rate $(60 \%)$, possible survivor bias (women from poor backgrounds may be more likely to die prematurely), and recall bias (indicators of childhood SEP were determined retrospectively by selfrecall later in life). Yet, because each of these factors would lead to an underestimate of the effect of childhood SEP on pulmonary function in later life, the true effect is probably at least as strong and perhaps even greater than that detected by Lawlor and colleagues.

The analyses presented by Lawlor et al support a cross-sectional relationship between lower SEP in childhood and pulmonary function in adult life. Our group recently completed a longitudinal study of young adult pulmonary function in relation to childhood SEP. ${ }^{4}$ Using retrospective recall of parental education to examine childhood SEP as a predictor of change in pulmonary function in young adulthood, these longitudinal prospective analyses showed that childhood SEP predicted both baseline and subsequent levels of pulmonary function, as well as rates of decline in young adult women and men, even adjusting for current socioeconomic status, height, age, and age $^{2}$, asthma, parental smoking, and participant smoking. Although these two studies use quite different samples and different indices for SEP, the findings were consistent with an inverse relationship between childhood SEP and pulmonary function in both young and older adulthood.

\section{FUTURE RESEARCH}

To move forward, we need to draw on existing research focused on social disparities and other health outcomes and apply some of the lessons learned from this work to guide future research on SEP and pulmonary function. Building on research on other outcomes, we propose that future research on SEP and pulmonary function should take into consideration the following conceptual and methodological issues:

- how to measure SEP (in early life as well as adulthood)

- sample diversity;

- developmental implications;

- dose-response effects of SEP;

- mechanisms linking SEP and pulmonary function; and

- how best to examine the significance of such research for intervention.

\section{Measuring SEP}

There are many ways to measure SEP. Education, income, wealth, and employment type/status have been used individually or in combination. There is no best measure as each has strengths and drawbacks; ${ }^{56}$ rather, different measures are appropriate for different populations. For example, appropriate indicators of SEP depend on the age of the population studied. ${ }^{78}$ Moreover, income would be a poor measure in a population with a high prevalence of unemployment or disability.

A number of factors need to be considered when using SEP of caregivers as a proxy for early life SEP of the study participant. Some argue that the
SEP of the father determines family SEP more strongly because men tend to be the primary breadwinner. Others suggest that the SEP of the mother is a better indicator of the child's early life SEP because mothers tend to be the primary caretakers and thus have more shared environments with children. Using data from both parents may be even more informative but it can be difficult to find a way to combine them appropriately, and assumes that all children live with both their parents and not other caregivers. Others suggest that individual level early life SEP is only one piece of the story and that the larger social context such as the household and neighbourhood in which one lives each also add important insight to understanding the factors that influence health. ${ }^{910}$

\section{Sample diversity}

Factors such as race/ethnicity, gender, urban/rural place of residence, and geography may modify the relationship between SEP and life pulmonary function, which underscores the need to examine these questions in diverse populations. For example, educational attainment may not capture the full range of socioeconomic disparities in any given population; there may be differential economic and social returns for women (compared with men) and racial/ethnic minorities (compared with majority whites). Furthermore, the impact of poverty or low SEP may have a greater effect on those with other low social status positions. Even less well understood is whether there is an additive, multiplicative, or other effect of early life SEP in combination with other status indicators. ${ }^{11}{ }^{12}$ In future research it will be imperative to sample participants in a way which will make it possible to examine interactions of childhood SEP with gender and race. In secondary analyses of existing large epidemiological studies, measurement of early life SEP is often a function of the availability of measures. However, keeping these general concepts in mind will be helpful in interpreting results.

The even more interesting research question may be whether there is some feature of a particular indicator of SEP that seems to be driving its effects, or whether the general early life milieu matters more for later life health. Lawlor et al used several indicators of SEP: manual childhood social class, no bathroom in the childhood house, no hot water in the childhood house, no access to a car as a child, and having a shared bedroom as a child. Our paper used the highest education completed between the mother and father as a single indicator of SEP. While both 
papers found generally similar trends, more research focusing on the implications of different definitions of early life SEP on later life pulmonary function is needed.

In the study by Lawlor et al $l^{3}$ childhood SEP was derived from data reported retrospectively. While it is unlikely that pulmonary function influenced the recall of childhood disadvantage, this study design cannot shed light on questions related to the timing of disadvantage. For example, are there critical periods in the life cycle when early life SEP has the greatest effect? Purpose designed studies might track individuals starting at birth, identify childhood SEP using multiple indicators from multiple informants, and then track the development of health and disease over the life cycle.

\section{Developmental implications}

Understanding the relationship between SEP and pulmonary function requires a developmental framework. ${ }^{13}$ SEP-especially those factors related to incomemay change over the life span with upward mobility, job loss, or change in marital status. ${ }^{12}$ Pulmonary function is also dynamic across the life span, with rapid growth in early life, a plateau in young adulthood, and decline in later life. SEP may have stronger effects on pulmonary function during certain periods of childhood than in others. ${ }^{6}$ To understand whether and how early life SEP influences pulmonary function it is important to examine factors both longitudinally and during different periods in the life cycle (for example, young adulthood versus older adulthood). Prospective longitudinal studies would be particularly valuable in identifying periods of vulnerability related to social status indicators. Low SEP may contribute to accelerated "weathering" of pulmonary function and other health outcomes, ${ }^{14}$ causing impaired growth and early or rapid decline of pulmonary function.

\section{Dose-response relationship of SEP to pulmonary function and disease outcomes}

Is the relationship between childhood SEP and later life pulmonary function better characterised as a threshold or as a continuous graded effect? A threshold effect would mean that, past a certain amount of poverty, the negative effects of deprived early life conditions have no additional effect. Lawlor et al found that, with a greater number of indices of childhood poverty, there was greater lung function compromise What remains to be studied with their sample is whether at higher levels of childhood SEP there is a gradient effect of childhood SEP on later pulmonary function-that is, is there an incremental improvement in pulmonary function with each step up the SEP hierarchy? ${ }^{15}$ If so, this would suggest that there is something more than poverty as such that compromises pulmonary function, but also greater harm associated with life experienced at each step down in the social hierarchy.

\section{Mechanisms linking early life SEP and pulmonary function}

There may be numerous mechanism linking early life SEP and later life pulmonary function as reviewed previously. ${ }^{3}$ Although much research has been done on these various factors and how they relate to pulmonary outcomes (pulmonary function and also chronic disease states such as asthma and COPD), less research has examined how they may be shaped by SEP. Here again it is important in future work to take a developmental perspective. That is, the potential impact on a given mediator influenced by early life SEP may change over time as children undergo normal developmental changes. For example, Chen and colleagues ${ }^{6}$ argue that SEP differences in smoking may increase with age, compatible with the accumulation of negative effects over time.

\section{Examining the significance of the research for intervention}

While it is important to understand how these mechanisms operate, it is also important to acknowledge that early life SEP may be a "fundamental cause" of later health and disease. ${ }^{16}$ Even as interventions are targeted to modify mechanisms piecemeal-for example, reducing parental smoking or air pollution-because of the ubiquitous effects of SEP, new pathways may develop with equally deleterious effects. Thus, in addition to short term health interventions, public health practitioners must also have long term goals for eliminating root causes that contribute to early life deprivation (such as policies to redistribute wealth). ${ }^{17}$

\section{CONCLUSIONS}

Early life factors including social disadvantage are increasingly recognised as important determinants of health across the life cycle, although research focusing on respiratory health related to early life SEP is sparse. The paper by Lawlor et al contributes further to this growing area of scholarship and underscores the need for further studies. We hope that attention to the conceptual and methodological issues noted above will guide research aimed at better understanding these relationships, and inform interventions to ameliorate factors that compromise pulmonary function.

Thorax 2004;59:186-188. doi: $10.1136 /$ thx.2003.018929

Authors' affiliations

B Jackson, R J Wright, S T Weiss, Channing Laboratory, Brigham and Women's Hospital, Harvard Medical School, Boston, MA, USA R J Wright, Beth Israel Deaconess Medical Center, Harvard Medical School, Boston, MA, USA

L D Kubzansky, Department of Society, Human Development, and Health, Harvard School of Public Health, Boston, MA, USA

Correspondence to: $\operatorname{Dr} B$ Jackson, Channing Laboratory, 181 Longwood Avenue, Boston, MA 02115, USA

benita.jackson@channing.harvard.edu

During the preparation of this paper the authors were supported by grants from the National Heart, Lung, and Blood Institute (NHLBI) and Environmental and Health Sciences (ES). B Jackson and $S T$ Weiss were supported by HL07427; R J Wright was supported by K08 HL04187; and L D Kubzansky was supported by ES10932.

\section{REFERENCES}

1 Barker D, ed. Fetal and infant origins of adult disease. London: BMJ Books, 1992.

2 Davey Smith G, Hart C, Blane D, et al. Adverse socioeconomic conditions in childhood and cause specific adult mortality: prospective observational study. BMJ 1998;316:1631-5.

3 Lawlor DA, Ebrahim S, Davey Smith G. Association between self-reported childhood socioeconomic position and adult lung function: findings from the British Women's Heart and Health Study. Thorax 2004;59:199-203.

4 Jackson B, Kubzansky LD, Cohen S, et al. A matter of life and breath: childhood socioeconomic status is related to young adult pulmonary function in the CARDIA study. Int $J$ Epidemiol 2004 (in press).

5 Lynch J, Kaplan G. Socioeconomic position. In: Berkman LF, Kawachi I, eds. Social epidemiology. New York: Oxford University Press, 2000:13-35.

6 Chen E, Matthews KA, Boyce WT. Socioeconomic differences in children's health: how and why do these relationships change with age? Psychol Bull 2002; 128:295-329.

7 Berkman LF, Sally M. The measurement of social class in health studies: old measures and new formulations. IARC Scientific Publications, 1997:138:51-64.

8 Robert S, House JS. SES differentials in health by age and alternative indicators of SES. J Aging Health 1996:8:359-88.

9 Krieger N, Fee E. Social class: the missing link in US health data. Int J Health Serv 1994;24:25-44.

10 Wright RJ, Fisher E. Putting asthma into context: community influences on risk, behavior, and intervention. In: Kawachi I, Berkman LB, eds. Neighborhoods and health. New York: Oxford University Press, 2003

11 Kessler RC, Neighbors HW. A new perspective on the relationships among race, social class, and psychological distress. J Health Soc Behav 1986;27:107-15

12 Williams DR, Collins C. U.S. socioeconomic and racial differences in health. In: LaVeist TA, ed. Race, ethnicity, and health. San Francisco, CA Jossey-Bass, 2002:391-431.

13 Duncan GJ, Brooks-Gunn J. Income effects across the life span: integration and interpretation. In: Duncan GJ, Brooks-Gunn J, eds. Consequences of growing up poor. New York: Russell Sage Foundation, 1997 
14 Geronimus AT. Understanding and eliminating racial inequalities in women's health in the United States: the role of the weathering conceptual framework. J Am Med Women's Assoc 2001;56 $133-6$
15 Adler NE, Ostrove JM. Socioeconomic status and health: what we know and what we don't. Ann NY Acad Sci 1999:896:3-15.

16 Link BG, Phelan J. Social conditions as fundamental causes of disease. J Health Soc Behav 1995;(Extra issue):80-94.
Bioterrorism

\section{Bioterrorism: the lung under attack}

\section{R M Maynard, T D Tetley}

\section{Role of respiratory physicians in preparing for bioterrorist attacks}

B ioterrorism is a "hot topic"; a search of the literature and the internet reveals an explosion of publications, government strategies, and guidelines, as well as advice for the general public. Bioterrorism differs from "biowarfare" in the sense that the threat emanates from terrorist groups rather than nation states. Unlike conventional warfare, where the enemy, underlying circumstances and likely mode of warfare are known and understood, terrorism is less easy to predictbeing sometimes aimed against seemingly random targets with little regard for the lives of civilian victims or that of the perpetrator. Chemical and biological weapons are very effective agents for terrorists whose strategy is not only to injure but also to instil terror and disorder into daily life, which may have long lasting psychological, economic, and political consequences. The terrorist attacks on the World Trade Center on 11 September 2001 and subsequent deliberate release of anthrax into the community in the USA in October 2001 has focused our attention on the threat of terrorism. Thus, at the recent Winter Meeting of the British Thoracic Society, the British Association for Lung Research organised a symposium which they called "Bioterrorism: The Lung Under Attack". In addition, in this issue of Thorax O'Riordan and Smaldone address the need for preparedness by the respiratory community-particularly clinical and supporting services-to combat acts of terrorism. ${ }^{1}$

Germ warfare is not new. ${ }^{2}$ The Greeks and Romans polluted their enemy's drinking water with animal corpses; the dead bodies of plague victims were catapulted by the Tartars into Kaffa in the 14th century; the British distributed blankets from smallpox victims amongst local American Indian populations during the 18th century destroying a high proportion of the population; during the first World War Germany attempted to obstruct food supplies by infecting cattle with anthrax and glanders; during the second World War the British developed an anthrax bomb which was tested on the Island of Gruinard, as well as producing five million anthrax loaded pieces of cattle cake with the intention of dropping these over Germany to reduce meat supplies by $30 \%$. Remarkably, no chemical or biological agents were used as weapons during World War II.

Bioterrorism is often taken to mean terrorist acts that involve the use of biological materials such as bacteria, bacterial spores, and viruses. This is a limited definition: terrorists could elect to use a range of agents that lie along a spectrum from classical chemical warfare agents at one extreme to biologically viable particles such as bacteria at the other. The lung is a target for all compounds that can be dispersed as gases or aerosols, and chest physicians may be among the first to recognise and deal with casualties exposed to such compounds. Understanding the effects of these substances on the lung is therefore important.

\section{EFFECTS OF BIOTERRORIST AGENTS ON THE LUNG}

The lung's range of response to injury is limited-for example, bronchoconstriction and pulmonary oedema are the major effects of inhaled chemical compounds. This is well understood, but the absence of specific antidotes makes our therapeutic approach limited. Chlorine and phosgene are widely used industrial chemicals and, although they have been known to be very dangerous since before their large scale use in World War I, no specific antidotes to their effects have been found. ${ }^{34}$ It is a
17 Kubzansky LD, Krieger N, Kawachi I, et al. The burden of poor health: social inequality in the United States. In: Whitehead M, Evans T, Diderichson $\mathrm{F}$, et al, eds. Challenging inequities in health: from ethics to action. New York: Oxford University, 2001:104-21.

sad fact that our capacity to treat the effects of exposure to phosgene is little better today than it was in 1915. Why is this?

\section{Chemical agents}

One reason is that lung damaging compounds such as phosgene do not interact with a single pharmacologically defined receptor. On the contrary, they damage cell membranes and inhibit a range of vital enzyme systems. ${ }^{3}{ }^{4}$ If we knew better the biochemical pathways involved, then developing specific antidotes might be possible. One line of attack is to oppose free radical generation by replacing depleted antioxidants such as glutathione. Some success has been achieved in animal models but little clinical benefit has been reported. Another approach is to treat the inflammation that may occur: the case of steroids has been strongly supported by some authorities but, again, hard evidence of efficacy in man is lacking. The increase in pulmonary capillary permeability produced by phosgene cannot be reversed by drug treatment. Support of adequate exchange of oxygen and carbon dioxide is vital and the use of positive end expiratory pressure ventilation has long been recommended. Recent animal studies have shown the value of limiting the tidal volume while maintaining an adequate minute volume in the management of respiratory failure caused by exposure to phosgene (personal communication, Dr Paul Rice, 2003).

Mustard gas (sulphur mustard) is an alkylating vesicant which may be dispersed by aerosolisation and slowly vaporises. ${ }^{34}$ It can be synthesised with limited equipment. Unlike chlorine and phosgene which reach the distal respiratory units, mustard gas deposits in and damages the conducting airways and adjacent alveoli. Stripping of epithelium occurs and infection may follow. Again, there is no antidote. However, although the effects may be severe, the lethality of exposure to mustard gas is likely to be low: during World War I only $1-2 \%$ of those exposed died later.

Nerve agents (nerve gases) which date from the 1930s occur as more or less volatile liquids and are the most toxic of the classical chemical warfare agents, causing death at very low doses. The case of the nerve agent sarin (GB, isopropyl methylphosphonofluoridate ${ }^{34}$ ) released by a religious terrorist group in 
Japan in the mid 1990s showed that well organised and well funded groups can produce deadly compounds in sufficient quantities to kill or injure large numbers of people. Because the mechanism of action of nerve agents is understood, there are a number of drugs available but treatment should be rapid. Prolonged ventilatory support may be needed for those who survive the initial exposure.

The use of chemical agents by terrorists should not be confused with the potential military use of such compounds - and even more so of biological agents-as weapons of mass destruction. It is more likely that the use of chemicals by terrorists would produce a limited number of casualties, the death rate depending on the compounds deployed and the extent of exposure both in terms of the concentration-time product and the number of people affected. Development in understanding the mechanisms of action of chemicals that might be used will aid in the development of rational treatment, although this will often be mainly supportive.

\section{Biological agents}

Biological materials that may be used by terrorists include bacteria such as Bacillus anthracis (anthrax), ${ }^{2-4}$ viruses such as Variola major (smallpox), ${ }^{24}$ and biological toxins such as ricin. ${ }^{3-5}$ Ricin is a less well known compound but was studied extensively as a potential warfare agent during World War II and was used in the assassination of the Bulgarian journalist Georgi Markov in London in 1978. It is derived in relatively large quantities during processing of castor oil from Ricinis communis seeds. ${ }^{5}$ Ricin is highly toxic: the lethal dose in man may be less than $1 \mathrm{mg}$ (injected). Importantly, it is particularly toxic when inhaled, causing fever, chest tightness, dyspnoea, and cough within 4-8 hours. It is believed that death is due to multiple organ failure. Treatment is supportive.

Bacillus anthracis occurs commonly in the environment, but terrorists would need the technical expertise to obtain virulent strains, purify spores, and develop an effective dispersal system. ${ }^{2}$ However, the events of October 2001 show that this is possible. A problem with identification of an anthrax attack involving exposure by inhalation is that the early symptoms resemble "flu" and treatment has a poor prognosis if delayed. This is complicated by the lack of clinical trials and the possibility of resistance to antimicrobial agents. Despite access to antibiotics, five of 11 patients who contracted anthrax died in the October 2001 incident. Rapid identification of anthrax exposure and antimicrobial therapy within the first week considerably improves the prognosis.

The smallpox virus would be very much more difficult to obtain as it is known to be kept in only two places in the world; however, it may be that there are other stores. ${ }^{2}$ Current stores of vaccine were produced from animal lymph and have been in storage for over 20 years. Recent use of these vaccines (by Israel and the USA) has highlighted some previously expected side effects, most notably myopericarditis. ${ }^{\circ}$ Consequently, new safer vaccines and safer vaccination strategies need to be developed and stockpiled to ensure effective rapid vaccination following exposure. ${ }^{26}$ In addition, since its eradication, smallpox might not immediately be recognised by younger physicians.

The effects of inhaled particles on the lung following the terrorist attack on the World Trade Center in September 2001 were also addressed at the BTS/ BALR symposium under the broad umbrella of bioterrorism. In addition to the thousands of people who were killed immediately, there were also exceptional environmental hazards for residents and workers in New York City. The collapse of the World Trade Center released huge quantities of material into the air and the plume of debris and smoke engulfed and contaminated a large area. Although the ambient concentration of fine particulate matter (which would affect peripheral lung regions) rarely exceeded government guidelines, the larger particles-which are not subject to regulation and which contained irritants such as fibre glass and were alkaline-caused respiratory irritation (for example, "World Trade Center cough"), ${ }^{7}$ probably due to effects on the large airways. In addition, new onset respiratory symptoms are significantly higher in those who live near the World Trade Center, while a small subset displays more bronchial hyperresponsiveness.

\section{HOW SHOULD RESPIRATORY PHYSICIANS PREPARE FOR BIOTERRORIST ATTACKS?}

An ongoing theme of the BTS/BALR meeting was the necessity for the emergency services, hospitals, and physicians to be prepared. ${ }^{4}$ It is important that decontamination is rapid and effective, and that none of those providing aid becomes contaminated in the process. Thus, staff must be protected and must be able to work in protective clothing. Furthermore, they must be able to use specialist equipment, which requires training and practice, and have access to appropriate therapeutic agents. $\mathrm{O}^{\prime}$ Riordan and Smaldone ${ }^{1}$ stress the need for a cohesive strategy by respiratory societies such as the British Thoracic Society to ensure rapid identification of respiratory symptoms consistent with an act of bioterrorism, to summon a rapid and effective response, and to promote the need for respiratory research in the area. That chest physicians should be familiar with recent developments in this area is beyond doubt.

Thorax 2004;59: 188-189.

doi: $10.1136 /$ thx.2003.016659

\section{Authors' affiliations}

R M Maynard, Department of Health, Skipton House, London Road, London SEI 6LH, UK T D Tetley, National Heart \& Lung Institute, Imperial College, Dovehouse Street, London SW3 6LY, UK

Correspondence to: Dr T D Tetley, Lung Cell Biology, National Heart \& Lung Institute, Imperial College, Dovehouse Street, London SW3 6LY, UK; t.tetley@imperial.ac.uk

\section{REFERENCES}

1 O'Riordan TG, Smaldone GC. Respiratory medical societies and the threat of bioterrorism. Thorax 2004; 58:265-7.

2 Beeching NJ, Dance DAB, Miller ARO, et al. Biological warfare and bioterrorism. BMJ 2002;324:336-9.

3 Greenfield RA, Brown BR, Hutchis JB, et al. Microbiological, biological, and chemical weapons of warfare and terrorism. Am J Med Sci 2002;323:326-40.

4 White SM. Chemical and biological weapons. Implications for anaesthesia and intensive care BrJ Anaesth 2002;89:306-24.

5 Lord MJ, Jolliffe NA, Marsden CJ, et al. Ricin. Mechanisms of cytotoxicity. Toxicol Rev 2003;22:53-64.

6 Chen RT, Lane JM. Myocarditis: the unexpected return of smallpox vaccine adverse events. Lancet 2003;362:1345-6.

7 Chen LC, Thurston G. World Trade Center cough. Lancet 2002;360(Suppl):s37-8. 